\title{
Thakirni Application: An Assistive Application for Alzheimer Patients
}

\author{
https://doi.org/10.3991/ijoe.v16i15.18063
}

\author{
Ruba M. AlSalah ( ${ }^{\bowtie}$ ), Asiya A. Salam, Madhawi A. Alzamil, Reem M. Alaskar \\ Maisa K. Alyemni, Mada A. Alahmdi, Buthaina A. Alqahtani \\ Imam Abdulrahman Bin Faisal University, Dammam, Saudi Arabia \\ rmalsalaheiau.edu.sa
}

\begin{abstract}
In today's world, mobile applications are used widely in our daily life and many areas. One important usage of these applications is associated with the health care sector. Health care applications are growing rapidly in the app store and have significant importance. Alzheimer has been known as a common disease. Therefore, in this paper Thakirni application is proposed as an assistive application that provides many different features for the early stages of Alzheimer patients. This application enhances the doctor's operations by ensuring that their patients come to appointments and increases the focus on patient care by recommending Thakirni application to the patients. The application provides a tracking feature, reminder feature about medicine, important events, and appointments throughout the day and photo album.
\end{abstract}

Keywords - Bracelet; Application; Alzheimer; Mobile, Android

\section{$1 \quad$ Introduction}

Technology plays an important role in healthcare. As technologies for healthcare systems and, more specifically, mobile health (mHealth) advance grow at a great rate, healthcare has now become more accessible than ever. mHealth applications improve the management of several chronic diseases, one of which is Alzheimer disease.

Alzheimer disease is a common neurodegenerative brain disease that develops gradually and worsens over time. The most common early symptom is short-term memory issues where the patient faces difficulty in remembering recent events [1].

To overcome those problems, the application Thakirni is a mobile application that runs on Android operating systems, catered to patients in their early stages of Alzheimer's disease. It is designed to focus on helping track the patients and improve their condition through features that will assist the patient in their daily living activities, which will reduce the burden on their caregivers. Accordingly, the application will not only affect the patients but also their loved ones and caregivers. See Figure 1 that represents the proposed application in terms of its main entities. 


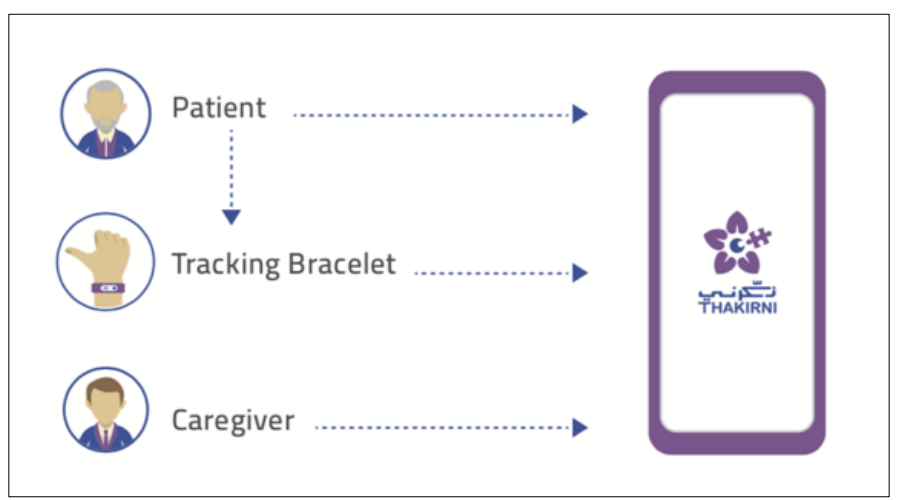

Fig. 1. Thakirni Application

\section{Problem Statement}

Alzheimer disease can cause memory loss and cognitive decline that mainly affect the elderly and can affect younger people as well. People affected by Alzheimer's have less ability to perform everyday activities such as losing track of time which causes changes in their sleeping habits without knowing, forgetting to take their medications or going to doctor appointments, high risk of wandering and getting lost as well as forgetting their family members faces and names. These symptoms develop gradually and worsen over time which leads to making patients more dependent on their caregivers. In response to this problem, Thakirni is proposed to offer several features for Alzheimer patients in the early to middle stages. We aim to assist Alzheimer patients in performing every day activities by reminding them of their important appointments such as medication and sleeping time. Besides, the application supports the integration of a wearable tracking device with our application to track the patient's location which will notify their caregiver in cases of emergencies, such as getting lost or exceeding a certain distance away from home.

Moreover, the application includes a feature that will dedicate a segment of each loved one that includes their photos, videos, and descriptions. This helps spark recognition in the patient of their loved ones and allow them to become more engaged with society. This application aims to help patients facilitate their way of living by making them less dependent on their caregivers and reduce the burden of the caregivers as well.

\section{Literature Review}

Many researchers propose mobile applications and tools to help Alzheimer's patients in their daily life [2], [3], [4], [5]. This section discusses some Alzheimer mobile applications that are used for monitoring Alzheimer's patients by caregivers and doctors. It describes how our application differs from other related applications. It 
briefly introduces similarities and dissimilarities between these applications and the proposed application.

\section{a) Alzheimer's Daily Companion}

Alzheimer's Daily Companion is an application that is used to provide support to patients via email or free phone calls, helping materials for patients and caregivers also, it works without an internet connection [2].

The application lacks GPS tracking, a reminder of the patient's everyday activities, an image album, or any feature to help patients in remembering their loved ones. Moreover, it focuses on helping the caregiver to deal with Alzheimer patients rather than focusing on the patients themselves.

\section{b) The Backup Memory}

The Backup Memory is an application that is used to detect nearby contacts of the patient stored in the application through Bluetooth and notify the patient about the user entrance. Moreover, it reminds patients about the type of relationship stored in their application contact list with a description, images, and videos of experience [3].

The application lacks GPS tracking besides a reminder for the patient's everyday activities.

\section{c) I-Wander}

I-Wander is a mobile application that focuses mainly on determining the probability of patient wandering by collecting data from the phone sensors such as GPS, time, weather, dementia stage, and user feedback. Then based on the probability of wandering, it navigates the patient to a safe location, sends a notification to the caregiver, provides the patient's current location, and calls emergency 911 [5].

This application does not provide any cognitive functions support such as a reminder.

\section{d) Alz Helper}

Alz Helper is a mobile application that acts as a communication bridge between the patient and the caregiver. It provides multiple features such as a backup of the patient's memory. It shows detailed personal information to patients such as acute memory loss due to the disease, sends a notification to remind the patients about medication, appointments, and current location. Besides, the caretaker receives a notification and sounds an alarm about the patient's current location, and in case of sudden memory loss, it provides pop-ups and alarms for the patient's current location and sends a notification to both the patient and caretaker [6].

This application does not provide any reminder feature that can help patients remember their daily schedule. Also, it depends on the phone solely to solve the wandering problem; Alzheimer patients may forget to take their phones. 
e) Pill Reminder

Pill Reminder is an application that is used to remind patients to take their medication at the right time with offline support It provides flexible scheduling options, refills reminder, and pill tracker. Another important feature is to lookup pills' information and identifies pills [6].

The application lacks a reminder to other events: it is restricted to medication only. Also, the application is limited to the reminder feature. The application does not also include an album or a tracking system.

\section{f) Life 360}

Life 360 is a mobile application that provides a GPS phone locator and a real-time tracking system through the application where the user can add his/her loved ones to track their locations. It also provides a family location history and adding important places to the map. One of its main features is the ability to share photos and messages with the user's loved ones [7].

This application does not provide any tracking hardware other than the phone such as a bracelet. Also, the application lacks the reminder feature which can remind patients of their important events such as medication time and sleeping.

\section{g) Where? When? What?}

In this application, the main feature is to remind the patient of the things that might be forgotten in a note and a reminder for any upcoming event [8].

This application lacks a tracking feature. There is no specific section in the application for pill reminders or an album to remind Alzheimer's patients of their loved ones.

\section{h) AD cope Application}

This application [9] utilizes mobility and advanced communication features of smartphones to rehabilitate $\mathrm{AD}$ patients. $\mathrm{AD}$ cope integrates quality of life enhancing modules such as the memory wallet, calendaring, and NFC enclosure content tagging, and dementia exercising modules that incorporate audio assisted memory training and spaced retrieval exercises.

This application provides most of the features, but it does not support a tracking feature that helps to notify the caregiver about the patient and lacks the reminder.

Table 1 summarizes the differences between the above applications and the Thakirni application. 
Table 1. Comparison between mobile applications based on selected features

\begin{tabular}{|l|c|c|c|c|c|c|c|c|c|}
\hline \multicolumn{1}{|c|}{$\begin{array}{c}\text { Features/ } \\
\text { Apps }\end{array}$} & $\boldsymbol{A}$ & $\boldsymbol{B}$ & $\boldsymbol{C}$ & $\boldsymbol{D}$ & $\boldsymbol{E}$ & $\boldsymbol{F}$ & $\boldsymbol{G}$ & $\mathrm{H}$ & Thakrini \\
\hline $\begin{array}{l}\text { Contact patient via E- } \\
\text { mail /Mobile phone }\end{array}$ & $\sqrt{ }$ & $\mathrm{X}$ & $\mathrm{X}$ & $\mathrm{X}$ & $\mathrm{X}$ & $\sqrt{ }$ & $\mathrm{X}$ & $\mathrm{X}$ & $\sqrt{ }$ \\
\hline No internet required & $\mathrm{V}$ & $\mathrm{X}$ & $\mathrm{X}$ & $\mathrm{X}$ & $\mathrm{X}$ & $\mathrm{X}$ & $\mathrm{X}$ & $\mathrm{X}$ & $\sqrt{ }$ \\
\hline Provide help materials & $\sqrt{ }$ & $\mathrm{X}$ & $\mathrm{X}$ & $\mathrm{X}$ & $\mathrm{X}$ & & $\mathrm{X}$ & $\sqrt{ }$ & $\sqrt{ }$ \\
\hline $\begin{array}{l}\text { Remind the patient } \\
\text { through a picture or } \\
\text { video }\end{array}$ & $\mathrm{X}$ & $\sqrt{ }$ & $\mathrm{X}$ & $\mathrm{X}$ & $\mathrm{X}$ & $\mathrm{X}$ & $\mathrm{X}$ & $\sqrt{ }$ & $\sqrt{ }$ \\
\hline $\begin{array}{l}\text { A reminder of the daily } \\
\text { schedule }\end{array}$ & $\mathrm{X}$ & $\mathrm{X}$ & $\mathrm{X}$ & $\sqrt{ }$ & $\sqrt{ }$ & $\sqrt{ }$ & $\sqrt{ }$ & $\mathrm{X}$ & $\sqrt{ }$ \\
\hline $\begin{array}{l}\text { Determine probability } \\
\text { of patient wandering }\end{array}$ & $\mathrm{X}$ & $\mathrm{X}$ & $\sqrt{ }$ & $\mathrm{X}$ & $\mathrm{X}$ & $\mathrm{X}$ & $\mathrm{X}$ & $\mathrm{X}$ & $\sqrt{ }$ \\
\hline Monitor patient location & $\mathrm{X}$ & $\mathrm{X}$ & $\sqrt{ }$ & $\sqrt{ }$ & $\mathrm{X}$ & $\sqrt{ }$ & $\mathrm{X}$ & $\mathrm{X}$ & $\sqrt{ }$ \\
\hline $\begin{array}{l}\text { Provide personal infor- } \\
\text { mation and history }\end{array}$ & $\mathrm{X}$ & $\mathrm{X}$ & $\mathrm{X}$ & $\sqrt{ }$ & $\mathrm{X}$ & $\mathrm{X}$ & $\mathrm{X}$ & $\mathrm{X}$ & $\sqrt{ }$ \\
\hline $\begin{array}{l}\text { Wearable tracking } \\
\text { device linked to the } \\
\text { application }\end{array}$ & $\mathrm{X}$ & $\mathrm{X}$ & $\mathrm{X}$ & $\mathrm{X}$ & $\mathrm{X}$ & $\mathrm{X}$ & $\mathrm{X}$ & $\mathrm{X}$ & $\sqrt{ }$ \\
\hline
\end{tabular}

\section{Motivation}

Creating a useful application for people with chronic diseases was the main motivation behind choosing Alzheimer patients for this application. Technology has changed everyone's life; we believe that it is our responsibility to ensure a healthy lifestyle for Alzheimer's patients as well as their loved ones and improve the overall quality of their life as much as we can. This motivates the need to develop a simple user-friendly mobile application with interactive GUIs.

\section{$5 \quad$ Methodology}

Thakirni application uses the waterfall software development methodology. The waterfall model is a sequential step methodology that is composed of seven steps. These steps must be followed respectively non-overlapping to deliver the final software product. Following are the phases of SDLC waterfall methodology:

1. Planning and Gathering Requirements

2. Analysis

3. Design

4. Implementation

5. Testing

6. Releasing

7. Maintenance

Each output of these phases represents an input for the next phase in the Thakirni application. The milestones for this project will go through each phase in the SDLC. 
For the implementation part, there are specific tools used:

\section{Android studio platform}

Android Studio is an Integrated Development Environment (IDE) for Android development. Android Studio offers many features that ease and improve the implementation process.

\section{Java programming language}

Java language will be used to write the code for each interface.

\section{Firebase database}

Firebase is a tool used to share data and synchronize the data in a real-time manner.

\section{$6 \quad$ Architecture}

Patients and caregivers are internal entities where they can access a wide variety of functions of the Thakirni application. It facilitates their daily lives and keeps patients tracked through GPS tracking bracelets which eases the finding of the patient in case of a wandering problem. See Figure 2, it illustrates the application's architecture.

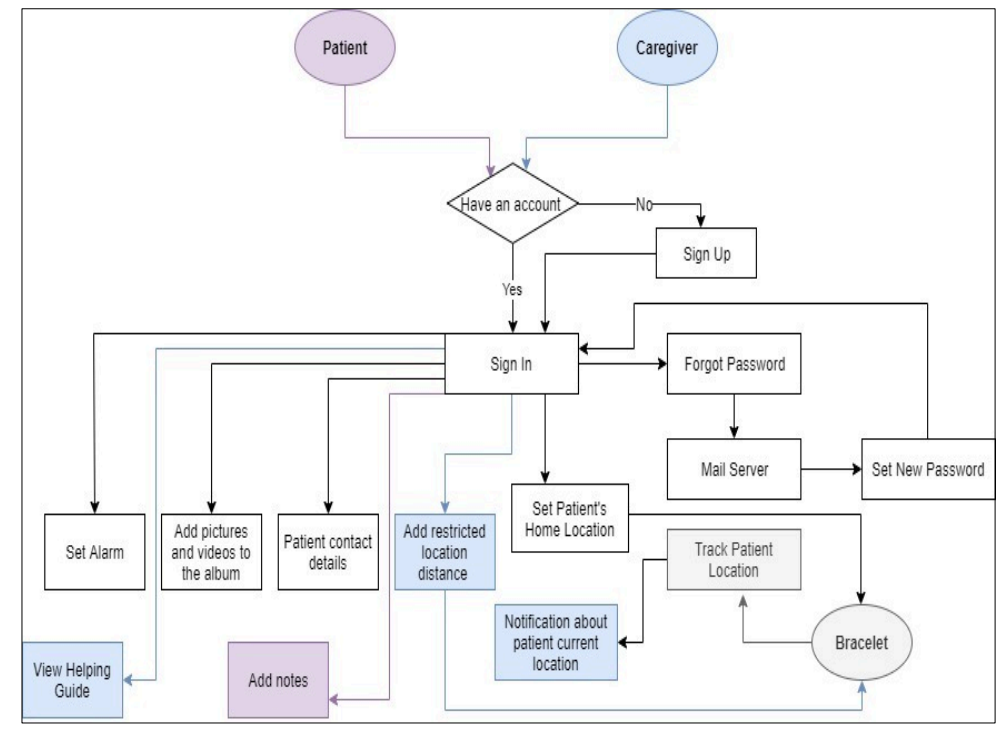

Fig. 2. Architecture of Proposed Application 


\section{$7 \quad$ Implementation}

Thakirni application is an assistive application for Alzheimer's patients that runs in the Android operating system and it is integrated into the patient's wearable bracelet. This application is implemented to help Alzheimer's patients and their caregivers. Caregivers monitor the patients through the application.

Figure 3 shows the main page of the application.

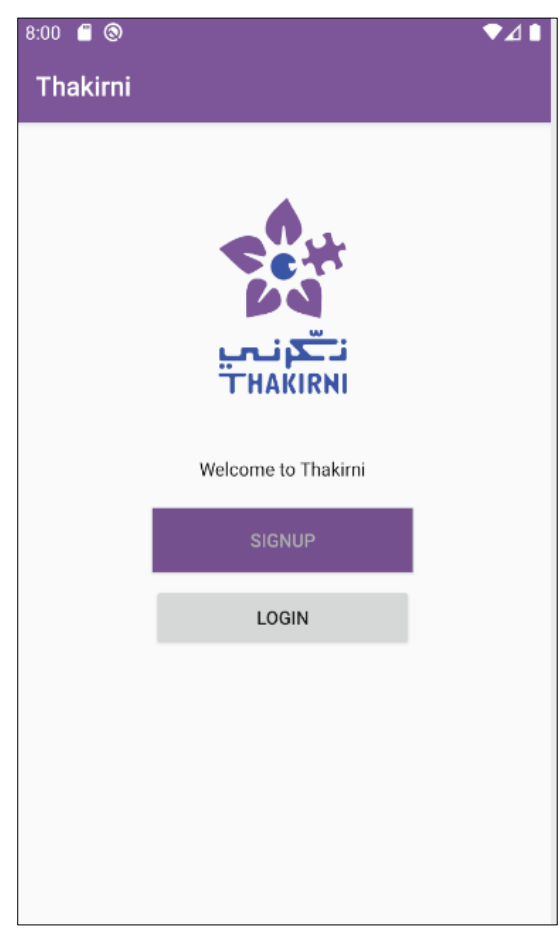

Fig. 3. Thakirni Main Page

There are two different interfaces of this application, one for the patient and the other one is for the caregiver.

\subsection{Sign-in interface}

The sign-in interface is used by both the patient and the caregiver by entering the email and password to authenticate and authorize the users. Then each user is directed to his / her home page depending on their level of authority. Figure 4 shows the login page of the application. 


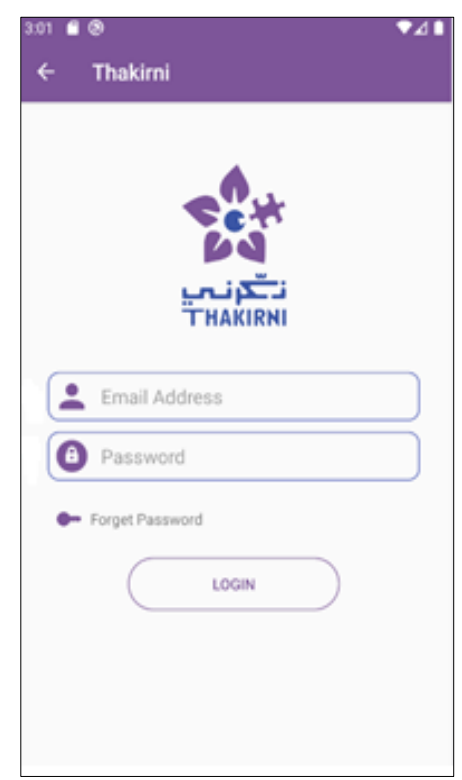

Fig. 4. Login Page

This home page appears when the caregiver or the patient accesses the application. It contains all the functions they can perform as shown in Figure 5 and Figure 6.

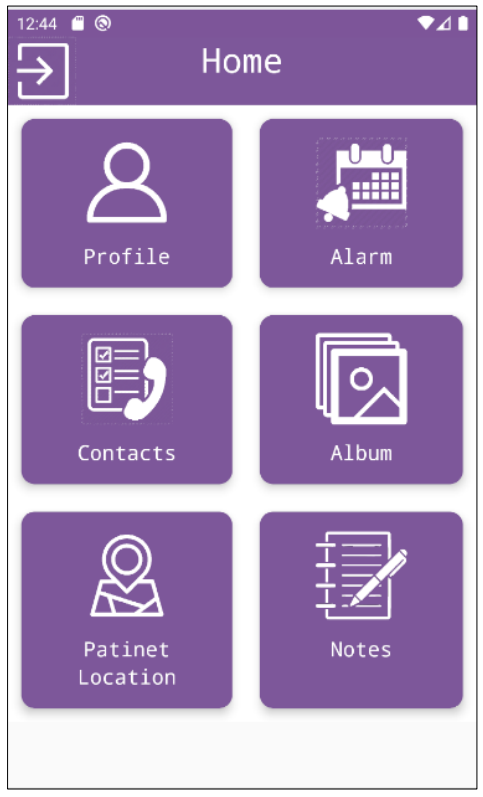

Fig. 5. Caregiver Home Page 


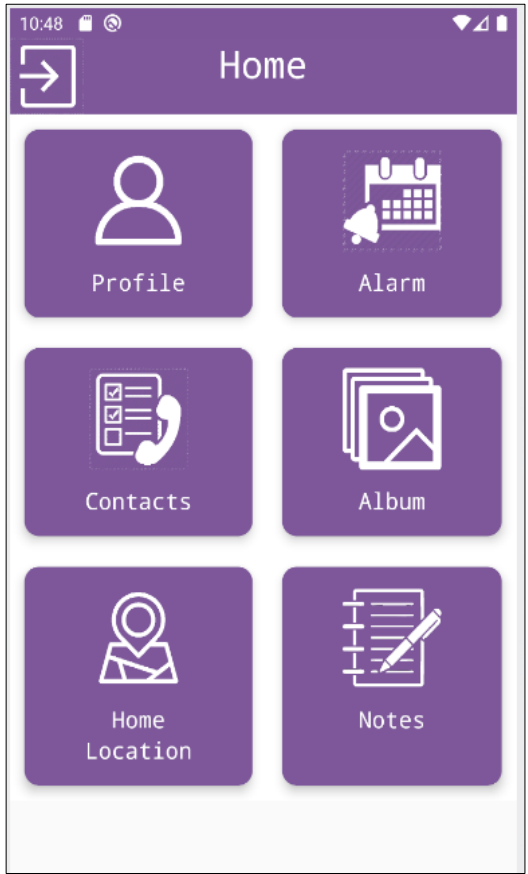

Fig. 6. Patient Home Page

\subsection{Contacts details interface}

This interface is accessed by both the patient and the caregiver. It includes contact numbers, images, and descriptions.

\subsection{Reminding alarm interface}

This interface is accessed by both the patient and the caregiver to set and schedule medicine time, gathering time, and any event that the patient should remember. Patients and caregivers will also be able to add a description for each reminder and set the reminder's time and date.

\subsection{Pictures and videos album interface}

This interface is accessed by both the patient and the caregiver to add photos and descriptions to the photo in the album.

\subsection{Monitor the patient's location interface}

This interface is used only by the caregiver to track and monitor the location of the patient. 


\section{$8 \quad$ Main Result and Significance of the Study}

Initially, Thakirini application was evaluated by the trials on Alzheimer patients. The application appeared beneficial for early stage patients. The cognitive functions were improved in the daily activities using this app. This rehabilitation of Alzheimer disease patients can provide support to the caregivers and help the patients in thinking, remembering, and reasoning using the alarm, albums and location tracking.

\section{Conclusion and Future Work}

This paper presents the work performed to develop a Thakirni application that improves and facilitates the daily life of patients who have Alzheimer in the early stages. Moreover, the application is designed to focus on helping the patients and improving their cognitive functions through features that assist their daily living activities, which will lead to reduce the burden on their caregivers. Therefore, the application does not only affect patients but also their loved ones and caregivers.

This application also intends to expand in the future with more features that will facilitate its usage and improve user experience by developing a facial recognition feature to facilitate recognition of loved ones, predict the patient's stage through analyzing how many times the patient gets lost, and provide functionality for late stages.

\section{References}

[1] L. G. Apostolova, "Alzheimer Disease," Continuum: Lifelong Learning in Neurology, pp. 419- 434, 2016. https://doi.org/10.1212/con.0000000000000307

[2] H. F. Association, "Download Daily Companion App," 2018. [Online]. Available: https://www.helpforalzheimersfamilies.com/get-help/download-daily-companion-app/ [Accessed 9 September 2019].

[3] S. G. Newsroom, "Samsung Volunteers in Tunisia Develop App for Alzheimer's Patients," 27 April 2015. [Online]. Available : https://news.samsung.com/global/samsungvolunteers-in-tunisia-develop-app-for-alzheimers-patients . [Accessed 9 September 2019].

[4] E. Yang, "Timeless," 2017. [Online]. Available: https://www.timeless.care/ [Accessed 9 September 2019].

[5] F, Sposaro; J, Danielson; G, Tyson, "iWander: An Android application for dementia patients.," Tallahassee, FL, 2010. https://doi.org/10.1109/iembs.2010.5627669

[6] S. Khedkar, H. Ahuja, H. Biradar, and A. Kulkarni, "AlzHelper: A Ubiquitous Application to Assist Alzheimer's Patients," IJIRST -International Journal for Innovative Research in Science \& Technology, vol. 3, no. 01, pp. 17-19, 2016.

[7] P. G. LLP, "Pill Reminder," 2018.

[8] B. Morin, 2018. [Online]. Available: https://www.life360.com/

[9] A. Zmily and D. Abu-Saymeh, “Alzheimer's Disease Rehabilitation using Smartphones to Improve Patients' Quality of Life", 7th International Conference on Pervasive Computing Technologies for Healthcare and Workshops, 2013. IEEE https://doi.org/10.4108/icst. pervasivehealth.2013.252248 


\section{Authors}

Ruba M. AlSalah is lecturer at the Department of Computer Information Systems, Imam Abdulrahman Bin Faisal University Dammam, Saudi Arabia. Email: rmalsalah@iau.edu.sa

Asiya A. Salam is lecturer at the Department of Computer Information Systems, Imam Abdulrahman Bin Faisal University Dammam, Saudi Arabia. Email: aasalam@iau.edu.sa

Madhawi A. Alzamil is with the Department of Computer Information Systems, Imam Abdulrahman Bin Faisal University Dammam, Saudi Arabia. Email 2160004356@iau.edu.sa

Reem M. Alaskar is with the Department of Computer Information Systems, Imam Abdulrahman Bin Faisal University Dammam, Saudi Arabia. Email 216004160@iau.edu.sa

Maisa K. Alyemni is with the Department of Computer Information Systems, Imam Abdulrahman Bin Faisal University, Dammam, Saudi Arabia. Email: 2160003561@iau.edu.sa

Mada A. Alahmdi is with the Department of Computer Information Systems, works in Imam Abdulrahman Bin Faisal University, Dammam, Saudi Arabia.2170007461@iau.edu.sa

Buthaina A. Alqahtani is with the Department of Computer Information Systems, Imam Abdulrahman Bin Faisal University, Dammam, Saudi Arabia. 2160001298@iau.edu.sa

Article submitted 2020-08-26. Resubmitted 2020-11-01. Final acceptance 2020-11-01. Final version published as submitted by the authors. 